From Making Futures by Pelle Ehn, Elisabet M. Nilsson, and Richard Topgaard (eds.)-MIT Press, 2014. CC:BY-NC.

\title{
3 Designing in the Neighborhood: Beyond (and in the Shadow of) Creative Communities
}

\author{
Anders Emilson, Per-Anders Hillgren, and Anna Seravalli
}

Living Lab the Neighborhood was initiated to explore how a platform that could facilitate social innovation and collaborative services could be set up in the city of Malmö. Although a few strategic decisions were made (for example, to adopt a long-term perspective that could go beyond single projects, to take a very inclusive approach to participation, and to build the platform from the needs, capabilities, and assets of local communities), the intention was that the platform should be designed and redesigned continuously in relation to what it encountered.

The platform is labeled as a living lab, a concept that originated at the Massachusetts Institute of Technology (Eriksson, Niitamo, Kulkki, and Hribernik 2005) and has been spreading rapidly around the world for about ten years. Today more than 400 labs are members of the European Network of Living Labs (ENOLL). There is no consensus on how to define a living lab (Følstad 2008; Stålbröst 2008), but usually such a lab is described as a long-term environment for open innovation that supports experimentation with real users in real contexts (Følstad 2008). This fits very well with what we see as essential in a platform that could facilitate social innovation. However, most living labs are strongly driven by industry and commercial interests, and that has consequences for how open "open innovation" can be (Kommonen and Botero 2013) and for what is regarded as innovation (Björgvinsson, Ehn, and Hillgren 2010, 2012). More than many other living labs, our platform is design-driven. According to some researchers, it is also one of few living labs driven by the interests of users' or citizen communities (e.g., NGOs) (Nystrom and Leminen 2011).

Living labs resonate with the idea of enabling platforms as formulated by designers in the field of design for social innovation. These platforms are looked upon as structures that should respond to the meta-technological demands of grassroots social innovations (Jégou and Manzini 2008). Manzini and Rizzo (2011) call these supporting structures "framework projects" and discuss what implications they might have for designers. According to Manzini and Rizzo, designers can act as facilitators and support ongoing initiatives, or they can act as triggers and start new initiatives. They can also be either design activists or members of co-design teams. We did not define any explicit roles the designer should take when exploring how the Living Lab the Neighborhood 
could contribute to social innovation, but we would argue that we have been working in all the roles described by Manzini and Rizzo. We have also taken an active role in matchmaking heterogeneous and complementary stakeholders to generate creative encounters. Focusing on different levels of design engagement has been important to our way of operating -we have sometimes zoomed in and paid attention to the details of concrete experiments together with grassroots communities, but when we have encountered obstacles to realizing the potential results of the concrete experiments we have sometimes zoomed out again to elaborate a possible change in the bigger picture by inquiring into more systemic levels by trying to modify regulations, work procedures and cultures, public policy, and indicators of project success.

We are not, however, the only ones who pay attention to these more systemic levels. Recently, several actors have started to explore how design potentially could have an impact on larger systems and, especially, how design could reach into the public sector and into municipal offices (Bason 2010; Christansen and Bunt 2012; Jégou et al. 2013; Staszowski et al. 2013). One inspiring example is La 27e Région, an independent innovation organization that explores how design approaches can influence policy development within the public sector in France. La 27e Région's strategy, which they have characterized as friendly hacking, builds on embedding multidisciplinary teams, including designers, who-for shorter or longer periods-can empower civil servants within diverse public organizations. They use the term 'hacking' because it "signifies the intent to challenge the robustness of public policy instruments" (Jégou et al. 2013, 6). "The hacking," they add, "is friendly, not destructive." Although most of our design interventions are based on concrete interventions at the community level, the concept of friendly hacking resonates well with how Living Lab the Neighborhood, as a metadesign platform, has focused more and more on building alliances within the public sector with the aim of having an impact on a systemic level. Our starting point has been quite different from that of La 27e Région. Since the beginning, they had several politicians sitting on their board, and their friendly hacking is commissioned by the public sector and supported by formal agreements that give them a mandate to work inside these organizations. We, by contrast, started far from power centers and rooted our initial work within local communities.

Apart from the more systemic recent engagements, the lab activities have focused on a variety of topics, on community needs, and on potential designs that include technology that increases grassroots organizations' visibility and mobile games for urban exploring (see chapters 11 and 14). During these processes, the concepts of infrastructuring, design things, and agonistic spaces have emerged and have helped us to better understand our activities. These concepts are discussed elsewhere in the present volume (e.g., chapters 2, 10, 11 on infrastructuring, chapters 2 and 14 on design things, and chapters 11 and 13 on agonism) and in recently published research papers by Björgvinsson, Ehn, and Hillgren (2010, 2012) and by Hillgren, Seravalli, and Emilson (2011). In this 
chapter we will focus on long-term infrastructuring, because the story we tell here is probably one of our most significant examples of such a process.

\section{Surprising findings from the city of Malmö}

To better understand our focus and what we try to aim for, consider the two quite different perspectives on Malmö that are described in the introduction to this book (see chapter 1). One highlights how the city has gone through an extensive transformation, from an industrial city to a "knowledge city" and a regional growth engine. The other perspective depicts it as a segregated city with a high number of immigrants who live primarily in the southeastern part, which has some of the highest rates of child poverty and unemployment in Sweden. In 2008, when we were engaged in research activities in Malmö's Rosengård district (famous for its social problems), riots were occurring and young people were attacking firefighters and police officers. The riots attracted international media attention.

According to the Kommissionen för ett socialt hållbart Malmö (Commission for a Socially Sustainable Malmö), these riots weren't surprising if one considered the huge differences in health and living conditions between Rosengård and other districts of Malmö. According to Stigendal and Östergren (2013), it is surprising that the tensions and troubles aren't worse.

We will come back to this later, but now we will start to describe the journey of designing Living Lab the Neighborhood. First, we will discuss whom we could collaborate with and how. We will then present a series of design interventions performed on different scales, stretching over several years, and financed by diverse funding schemes. Finally, we will discuss what this means as a design practice.

\section{Beyond (and in the shadow of) creative communities}

At the beginning of Living Lab the Neighborhood, two important questions were whom to collaborate with and which actors could have relevant capacity and skills to work creatively with social innovation. Concepts such as the creative class (Florida 2004) and lead users (von Hippel 2005) mainly bring forward privileged groups, such as engineers, poets, artists, researchers, or designers. These groups are well established and make up a significant percentage of the citizens in the western part of Malmö, where new-media clusters are emerging and where Malmö University is located. However, the starting point for our lab was to try to work with stakeholders and citizens that are living and operating in the southeastern part of the city. Although there are engineers, poets, and artists in these areas, we were particularly interested in locating people and groups that were not on Florida's or von Hippel's list. One promising alternative to the privileged groups-an alternative that inspired us at the time-was the concept of creative 
communities made up of "professionals of the everyday" (Meroni 2007)—people who have organized themselves to solve a local problem, often focusing on achieving local sustainable solutions.

Whereas the creative class is driven by highly individualistic norms (Florida 2004), the creative communities are driven by a sense of community spirit and by the pleasure of collaborating and building relationships (Meroni 2007). Most of the examples that Meroni brings up are tied to specific categories (for example, commuting, eating, and housing) and are aiming for a specific solution, such as a "walking school bus" (an arrangement by which children walk to school together). Creative communities are also quite visible in the urban landscape. Even if you might find examples in Malmö that more explicitly resemble these cases, we were curious if we could find other resourceful actors that were less visible. As we argued in the introduction to the present chapter, we aim for an inclusive approach that will allow marginalized actors to participate.

What kind of groups could be found "under the radar"? Every time we have asked civil servants about prominent creative groups or stakeholders in these areas, and every time we sent students out to do research, the same answers recurred: the most prominent actors were Drömmarnas Hus (an independent organization focusing on cultural activities such as theater and film, often in collaboration with schools) and Yalla trappan (a cooperative association of formerly unemployed immigrant women who provide catering and housekeeping services). Drömmarnas Hus and Yalla trappan are supported by the municipality, highly visible, and fairly well established.

How can those "under the radar" be reached? We had an infrastructuring process (Björgvinsson, Ehn, and Hillgren 2010, 2012; Hillgren et al. 2011) going on some years before the Neighborhood Lab started. Infrastructuring basically means that we cultivate long-term working relationships with diverse actors and slowly build a designing network. In this process, some stakeholders have been using their social capital to help us approach and enter other networks that are "under the radar" and marginalized. For example, Rörelsen Gatans Röst och Ansikte (RGRA), an organization with which we had been working for a long time, connected us to a marginalized but also highly innovative and skillful group, the Herrgård's Women's Association (HWA).

\section{The Herrgård's Women's Association}

HWA was founded in 2002 by five women in the Rosengård district of Malmö as a response to the feeling of being excluded from Swedish society. The organization counts approximately 400 members (200 of them children) with backgrounds in Iran, Iraq, Bosnia, and Afghanistan. Most of the women live on social security, have limited skills in Swedish, are illiterate, and generally lack higher education. HWA fulfills most of the characteristics of a creative community: the members' emotional involvement is tightly connected to a collective approach, and they have organized themselves to develop solutions for challenging problems in their neighborhoods. These problems 
are, however, slightly different than the ones that have been described by Meroni (2007). They include complex social problems that seldom are visible in the physical environment or outside their community. One issue is social integration, since many immigrants have a hard time being accepted in the Swedish society. Then there are gender issues in patriarchal cultures where the group slowly, but forcefully, has pushed the borders for what a woman is allowed to do. Moreover, through the trust that the women have developed within their networks during many years, they can mediate between family members to prevent honor-related violence and they organize educational events in collaboration with the city around health issues (e.g., sexual health). Here, we would like to connect back to the Commission for a Socially Sustainable Malmö (Stigendal and Östergren 2013) and argue that HWA and similar organizations probably are one of the reasons why riots and social problems aren't worse than they are. Their invisible everyday work mitigates many of the tensions.

In parallel to being engaged in these complex social and societal issues, the women's activities also include cooking, designing textiles, and making carpets and clothing. The core group of five women meets regularly, and, depending of what kinds of activities are carried out, other members sometimes participate.

If we would bring forward some more of the distinguishing qualities that these women possess, it would be the extensive social network and trust they have built in the area. They have the insider's perspective on what problems and opportunities are embedded within their communities. This gives them the ability to be very creative and to devise situated solutions to local problems in ways that outsiders (e.g., civil servants) cannot.

Another distinctive feature that Meroni (2007) assigns to creative communities is a feature that, we argue, applies well to HWA: their aesthetic qualities. Meroni states that creative communities "are not only interesting because they are innovative, but they are also aesthetically 'beautiful': there is something in the way they appear that invokes

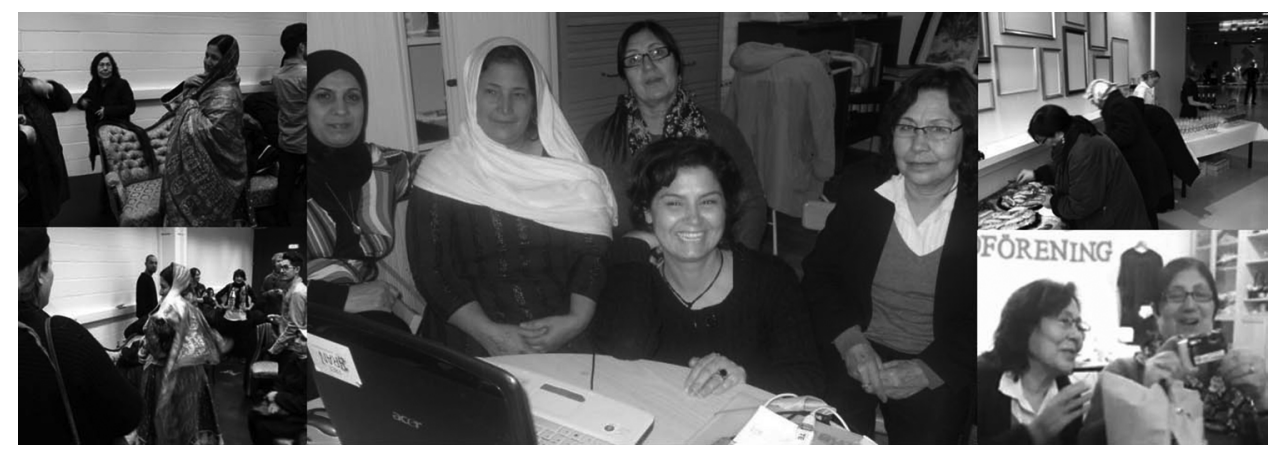

Figure 3.1

The Herrgård's Women's Association. Copyright Per-Anders Hillgren (CC:BY-NC). 
positive emotions and recalls the straightforward aesthetics of the useful. They are beautiful because they are colorful and they are authentically and surprisingly creative. They express vitality and spirit of initiative: they are the unthinkable made possible." $(2007,9)$ HWA is certainly colorful, authentic, and vital in the way that Meroni brings forward.

\section{An emerging framework project: Living Lab the Neighborhood}

Once we had identified HWA as a promising and challenging partner with a resemblance to a creative community, though much more in the margins, the next question was how we could work together. As Manzini (2007) argues, when you approach creative communities as a designer, you often do not need to design something new. The good ideas are already there, embedded in the practice, and you have to facilitate, support, and scale up what these groups already are doing. To be able to do that, Manzini and Rizzo (2011) argue, you need a framework project, a larger supporting structure that could move these local cases out of isolation and increase their capacity to contribute to society. The purpose is to see if these creative communities could inspire others, be replicated, and eventually have a large impact (ibid.). We explored how Living Lab the Neighborhood could become a framework project. However, it wasn't clear to us what should be scaled up or replicated, or if scaling and replication would be the right strategy at all. Rather, we wanted to collaboratively explore what the women wanted to do and, if possible, build relationships and connect them to diverse stakeholders. If strategic design and scenario building has been the central approaches for Manzini and Rizzo (ibid.) to construct framework projects, we have rather started from the local projects and having a framework project emerging bottom up. In line with Nabeel Hamdi's (2004) argument that overdesign often inhibits progress and development, we have tried to create a balance between defining a possible direction and allowing for emergence. Particularly through our processes of infrastructuring, we have been building relations with diverse actors through an ongoing matchmaking process, with flexible allocation of time and resources. This more organic approach tries to make use of the creative potential in a heterogeneous city by facilitating opportunities that emerge along the way. Infrastructuring allows the unexpected to emerge by working toward the creation of framework projects, which strive for being open-ended when it comes to constellations of actors (that is, who will participate) and issues (that is, what to explore and how to do it).

\section{Co-designing with HWA-no method, but artful inquiries}

Different methods that could spark creativity and organize discussions during workshops are often highlighted as cornerstones within co-design (Brandt 2006). The 
designer's role within co-design is to provide "tools for ideation and expression" (Sanders and Stappers 2008, 12). One of the arguments behind this focus is that people with different backgrounds and professional languages need tools to mediate and articulate the discussions during the design process. One might think that this would be especially relevant when approaching a multi-ethnic NGO with diverse cultural backgrounds. However, our experience turned out to be contrary to such expectations. Instead, we started our collaboration slowly with informal meetings, sitting down, drinking tea, and discussing one another's practices and everyday activities. They were not rushed and well-structured meetings, nor smart workshop formats, but very casual and openended appointments. Our design approach was rooted in the reflective practice of Donald Schön $(1983,1987)$ rather than in particular methods. During these encounters, we navigated among opportunities through a process of reflection-in-action and reached an understanding of the women's situation by continuously re-framing it. The process can be viewed, according to Schön, as consisting of "artful inquiries" that represent reflective conversations with unique and uncertain situations where standard theories or techniques cannot be applied. Because of language differences and cultural differences, the approach was to take it slow and let understanding develop. Many meetings between the women and representatives of the municipality have broken down, and our understanding is that the breakdowns have been attributable in part to difficulties in communicating and to the fact that civil servants don't have (or take) enough time to sit down and talk to the women and to the fact that they often set the agendas and the protocols for the meetings.

During the very fruitful discussions that took place during our meetings, the women expressed their desire to be more integrated in the Swedish society by finding opportunities for their abilities and skills to be valued. According to them, their activities were most often considered to be "leisure" by the authorities. This spurred our curiosity as to whether we, together with the women, could demonstrate that their activities could be viewed as "professional," and that an immigrant NGO could become a socioeconomic resource for the Swedish society. During this phase, we could have developed scenarios to highlight this possibility, but there were too many questions and potential issues that had to be resolved, and we needed a more explorative approach. The notion of reflective practice is seldom highlighted in the areas of design and social innovation. However, another concept from design, prototyping, has spread quite extensively (Burns et al. 2006; Brown and Wyatt 2010). According to Murray, Caulier-Grice, and Mulgan $(2010,12)$, refining and testing ideas is important in social innovation because "it is through iteration, and trial and error, that coalitions gather strength (for example, linking users to professionals) and conflicts are resolved (including battles with entrenched interests)." Prototyping has played a central role in the work with HWA (Hillgren, Seravalli, and Emilson 2011), and it often turned out to be a quite demanding and complex activity. All HWA interventions required mobilizing a number of stakeholders and 


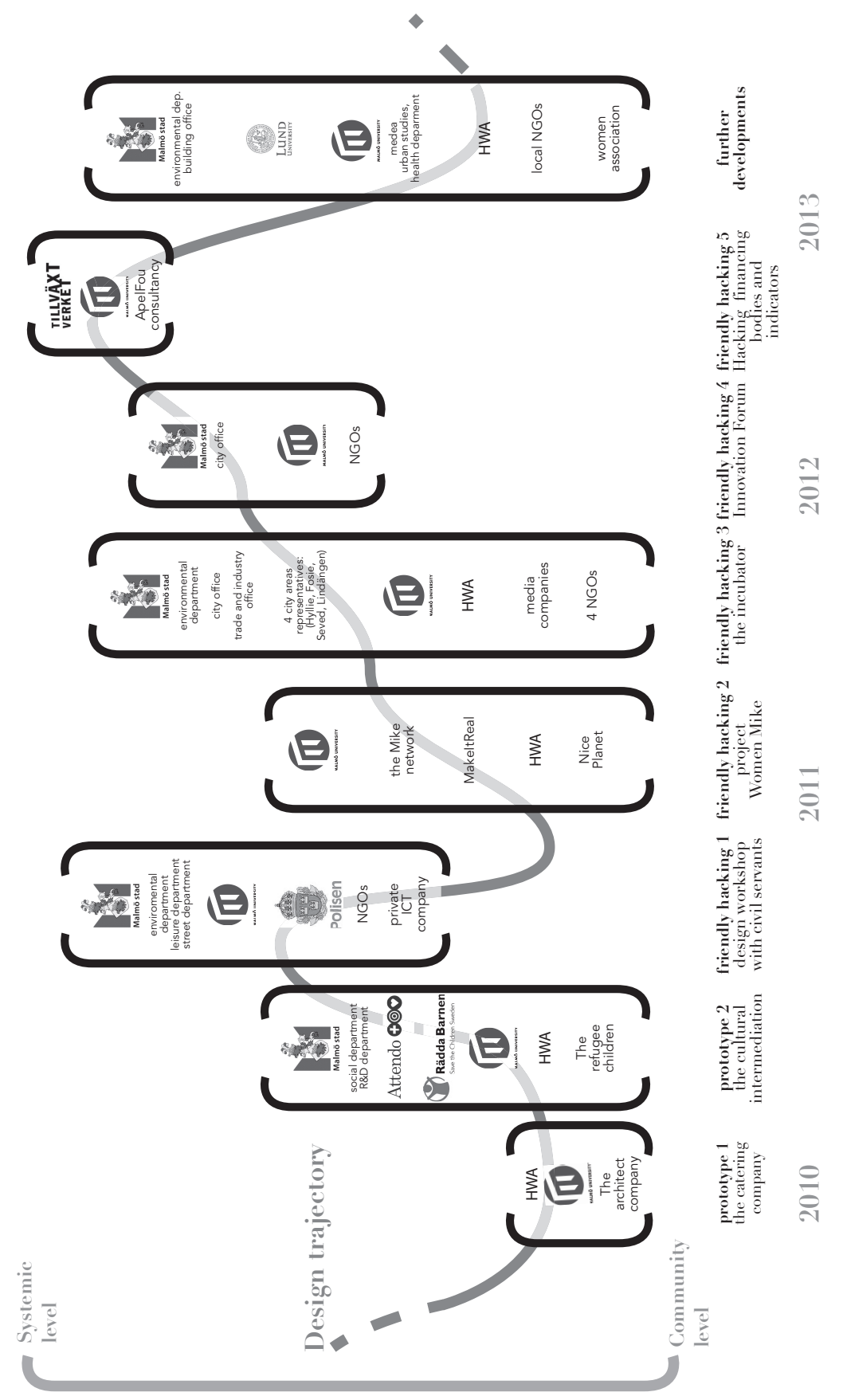

Figure 3.2

The long journey with HWA. Anna Seravalli (CC:BY-NC). 
asking them to invest time and resources. This had the implication that the expectations were often quite high, leading to a number of issues related to the actual results of each prototype, with failures being difficult to accept and manage.

In the subsections that follow, we discuss our long-term engagement with HWA and how artful inquiry with the women developed through the use of prototypes and through friendly hacking.

\section{Prototype 1: The catering company}

After a suggestion from HWA, our artful inquiry started by developing prototypes around their cooking activities. Initially, we tried to understand how their cooking skills could be developed into a service that besides the food also could include knowledge about the food ingredients and the original cultural context. We also explored if the women could play a more active role when delivering the food than just handing it over. Facilitated by us, the women produced leaflets about the food to be distributed to the clients, and we supported them in getting a few catering orders. For example, we put them in contact with an architectural firm, and we accompanied them to an event at which they provided some tastes of Afghan and Iraqi food to employees at the architectural firm.

The architects clearly expressed their enthusiasm about the additional cultural experience and quickly adopted the Afghan terminology_-for example, "Could you please bring me one more Kobbe?" It seemed that both HWA and the architectural firm were satisfied and that the studio would place the order, so we stepped back, leaving the women doing their business. Unfortunately, a few days later HWA informed us that the architects had turned down their offer, apparently because they thought that HWA was too expensive. We phoned the studio and discovered that communication problems had arisen: the company was asking the women to provide a formal offer, stating the menu and the quantity of food they would deliver. The women were not used to these kind of requests, and something went wrong in the communication between the actors: the architects thought that the quantity of food HWA would deliver would not be fair in relation to the price.

In hindsight, it is clear that we should have helped the women to structure and communicate their offer. However, during prototyping with HWA, it has always been problematic to find a balance between the support we should provide them while avoiding making the women feel weak, fragile, and too dependent on us. Nevertheless, the catering activity has developed further and it has become one of the central activities of HWA, even though the women lack access to a professional kitchen and thus have to do the cooking in their homes.

\section{Prototype 2: The cultural intermediation}

Early on, the women told us that they would like to try to do something for refugee children in Malmö. These kids, mainly between 13 and 17, are in Sweden without their 
families. Malmö has welcomed a lot of Afghan and Iraqi orphans in recent years, and, since they share the same cultural background, the women felt they could offer something to them. However, working with refugee children is a sensitive matter, and we wanted to facilitate the creation of trust between HWA and the responsible department of Malmö's municipal government. Together with us, the women proposed to the city that meetings with the refugee children could be held to explore whether HWA might be able to provide some kind of valuable service for them in the future.

The municipality was positive but didn't want to play an active role. They suggested that we should contact the health-care company Attendo, which provides accommodation for refugee children in Malmö. Attendo was positive and we set up some experiments. We were particularly concerned about the possibility that the prototyping activities might evoke some undesirable memories in the women and the children. We decided to proceed carefully. The first step was simply to invite the kids to HWA's premises for an Afghan meal. They came accompanied by an Attendo employee. It turned out that most of them had not been eating home-made Afghan food since leaving their families, sometimes several years before. It became clear that food could play an important role, and the kids wished that there would be other occasions for meeting the women and eating together. According to the women, several of the children were quite depressed, and to some degree the women were emotionally stirred, but the emotional experience was compensated by the joy of feeling helpful.

The next step was to offer a cooking class to the children. That was done in collaboration with a media company called Nice Planet, which provided access to its kitchen. During this encounter, the children could alternate between cooking with the women and using Nice Planet's computers to explore social media together with some of the company's employees. (See figure 3.3.) The experience was quite positive for all involved (the CEO of Nice Planet said "I feel extremely inspired by meeting the women"). A chance to establish a more solid connection between HWA and Nice Planet emerged, which opened up the possibility for the next step in the artful inquiry with HWA: a possible collaboration between the women and the Mike Network, a Swedish network of businesswomen. (Nice Planet's CEO was a member of the Mike Network.) Making the necessary arrangement with the Mike Network took some time. Meanwhile, we tried to get civil servants from the city of Malmö involved in the effort.

\section{Friendly hacking trial 1: A design workshop with civil servants}

A role for designers that often is mentioned in relation to social innovation is to support capacity building, in which communities get empowered with new skills that can facilitate their everyday efforts. When the designer leaves the scene, this capacity will remain within the communities (Burns et al. 2006; Sangiorgi 2011). However, it became more and more clear that the members of HWA, although they might need 


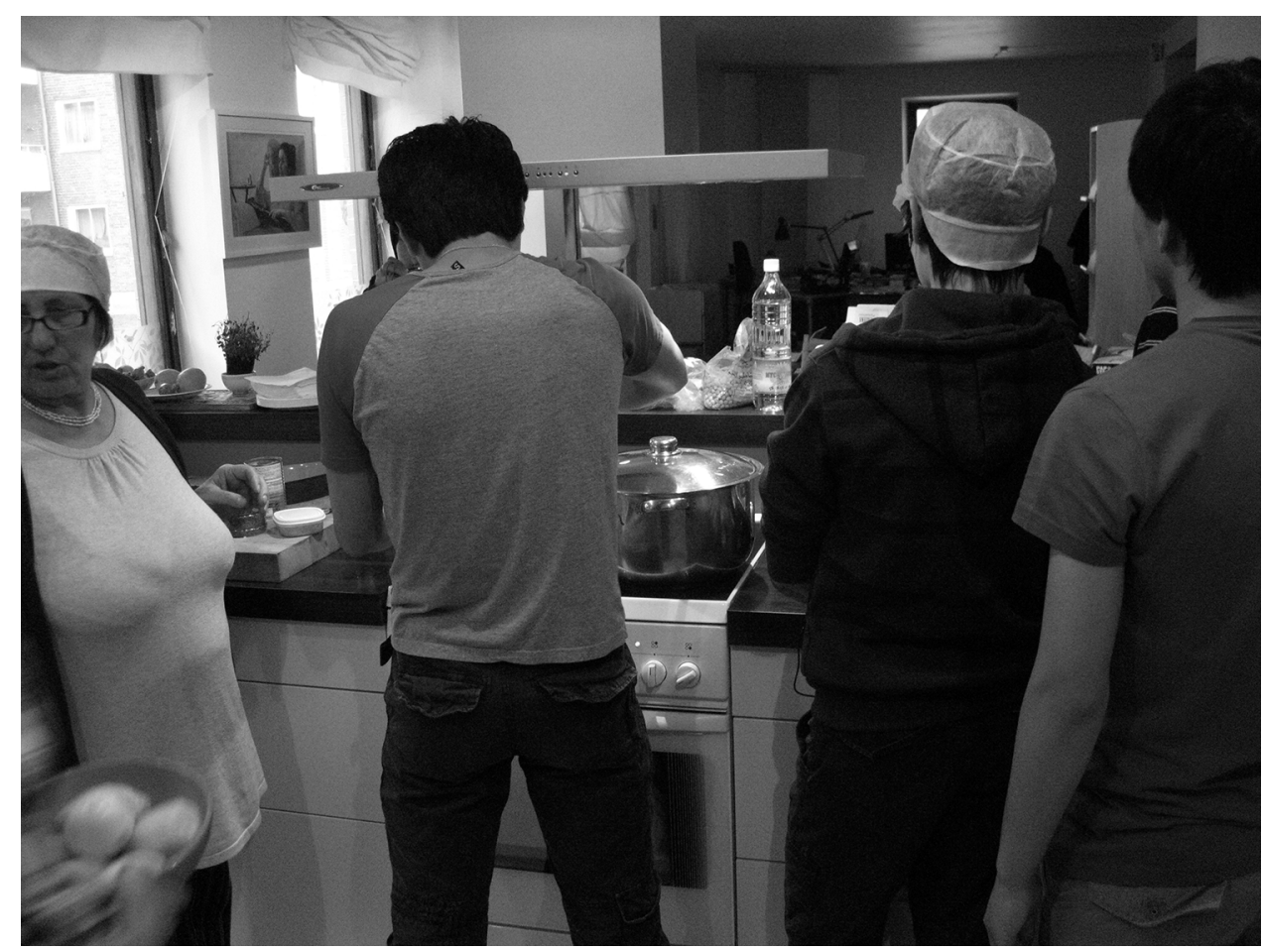

Figure 3.3

Refugee children cooking with a member of HWA. Per-Anders Hillgren (CC:BY-NC).

some support in doing business, were extremely capable and skillful. The reason why they still were regarded as a societal cost and as acting in the margins must thus be found elsewhere. From our perspective, it would rather be the municipality that needed capacity building and new skills for how to be able to support organizations like HWA. Consequently, from this moment, our attention to where to locate our design interventions shifted from the women toward the municipality, and our first opportunity for friendly hacking emerged. While we were slowly strengthening the women's relations with some civil servants, one of us was asked to participate in an internal municipal development group in the neighborhood in which the HWA members lived and operated. This position was then used to introduce, in the development group, the notion that municipal support for local communities could be valuable, which was received positively by a few civil servants. From this, we got a commission from the municipal government to hold a workshop on design and social innovation. The civil servants prepared the invitation list for the workshop, and HWA's members were not on it, but 
we sneaked them in by setting up a workshop assignment that was tailored to HWA's needs. The workshop seemed successful and provided many valuable findings for us. First of all, many of the civil servants questioned the vocabulary and practice of both design and social innovation, although some of them had had good experiences with grassroots initiatives. It also became clear that the municipality would have to rethink its practices for how to support NGOs and how to work with social innovation. Some prominent civil servants stated that there was a tension between formal structures and creativity, and that social innovation required them to work across departments. They also argued that there was a need for a more permissive culture, so that civil servants would be allowed to experiment and even to fail. They also discussed how regulations could be stretched, and what could be done without breaking any regulations or laws. Finally, specific scenarios were developed that described how community initiatives (similar to HWA) could be supported by the municipality through an iterative process. Several civil servants seemed very interested in exploring this further, and we expected the process to continue. However, nothing happened, and all our attempts to try to understand why nothing had happened failed. Some civil servants insinuated that the reason nothing had happened was cultural: that civil servants didn't want outsiders to interfere with their business. Although this could be seen as a failure, we learned some valuable things and acquired more allies.

\section{Friendly hacking trial 2: Project Women Mike}

While working with the municipality, we continued our conversation with the CEO of Nice Planet. She had been impressed by the women of HWA, and she wanted to find ways to work further with them. We wanted to foster collaborations between HWA and other extraordinary businesswomen, with the aim of strengthening HWA's business competence and, at the same time, challenging established notions of what could be regarded as a company or an entrepreneurial activity.

This new attempt involved the Mike Network (a Swedish organization that promotes peer-to-peer support between career women) and Make It Real (a side project of Nice Planet's CEO - a digital platform for connecting people with diverse competences for the purpose of developing projects). The idea was that Make It Real could facilitate encounters between HWA and the Mike Network with the aim of encouraging peer-topeer support between the women of the two groups.

We offered to help the founders of Make It Real, since we thought that our long experience with HWA could help. However, they clearly stated that they did not want us to intervene in the project. For Make It Real, the project was a fundamental step in proving that they were able to act as matchmakers; thus, in order to establish their role and state their ownership of the process, they did not want to collaborate with us in structuring the encounters. 
The Make It Real founders set up the process as a series of meetings between members of the two organizations. These meetings, mediated by a business coach, were aiming at developing a number of projects from "dreams and aspirations" of the participants.

The first meeting went rather well. The women got to know one another, then organized themselves into five groups focusing on activities that HWA was already carrying out, such as cooking and gardening. After the first day, each group had a series of meetings with the business coach to develop a project plan. In these encounters, it became apparent that it was difficult for HWA members to be able to attend all the planned meetings, because they were involved in several groups at the same time. Another issue was Make It Real's process structure, which was very traditionally business-focused and-already at the early stages—brought up questions such as "Who is your potential client?" and "What is your value proposition?" This approach turned out to be problematic for two reasons. First, it presumed a high commitment from the participants, while they barely knew one another. Second, although these question may sound quite

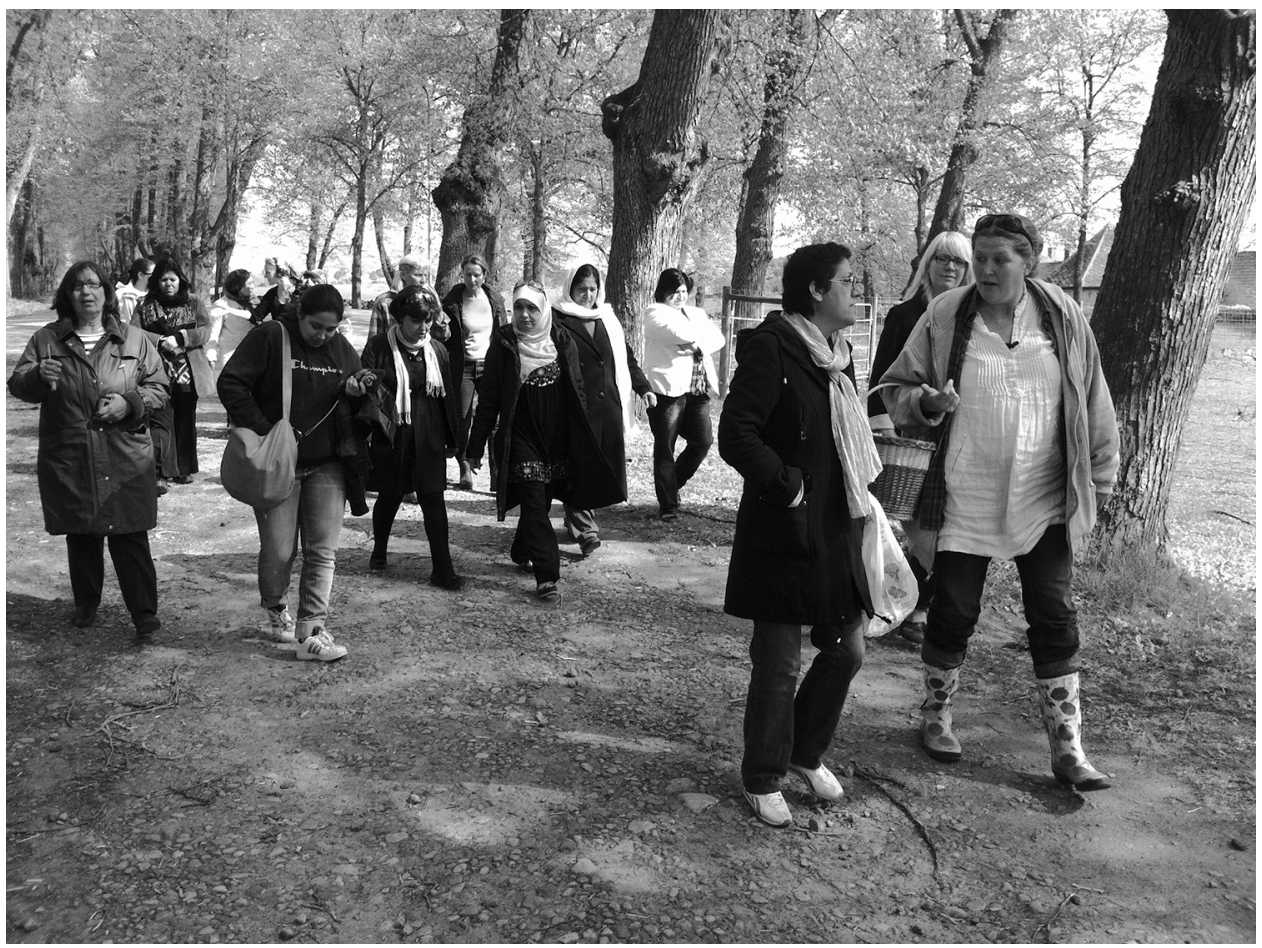

Figure 3.4

HWA and the Mike Network women out in the woods. Anna Seravalli (CC:BY-NC). 
standard and easy to answer, they were completely new to the HWA members, and far from how they were accustomed to framing their everyday activities.

One encounter that went quite well was a day trip organized by one of Make It Real's founders at her house in the middle of a forest. The women spent the day picking herbs and cooking together, getting a chance to get to know one another better. Unfortunately, only a few women of the Mike Network were able to participate in that encounter, since it took place on a working day.

The process continued for a couple of months; then there was a meeting at which the groups were asked to present their proposals. During this meeting, Make It Real stated that each group should develop its projects independently. Consequently, the coach asked the HWA women, who were participating in several groups, to choose one group over the others. This raised concerns among the HWA women, but in the end every participant was on board. Another series of encounters for each group were planned.

A few days after this meeting, someone had forced the door of the small building where HWA met, stolen a binder with the names and addresses of the members in it, and started a fire. This was the third time HWA's meeting place had been burned down, and this time the women were quite scared by the theft of the information about them. HWA asked that the Make It Real project be put on hold.

This break allowed some doubts about the project to emerge. Specifically, HWA members felt that splitting up in separate groups was endangering their NGO, since they were not working as a unit. At the same time, some of the members of the Mike Network complained about the HWA members' lack of commitment in the processthey were not present at all the meetings, they were often late, and they were not very active in formulating and developing the proposals. Through discussions with the participants, we came to understand that there were two main issues: that the process was too fast and that the HWA women considered themselves a collective.

With Make It Real, we discussed the possibility of modifying the process by slowing down its pace. However, the founders of Make It Real found that unacceptable. According to them, the idea of a collective was keeping the women from expressing their full potential. They were also quite frustrated-they had found a potential source of financing for one of the projects, and the break was spoiling their efforts to secure it. In addition, the members of Make It Real were eager to find economical resources that could help them establish their initiative. These tensions, accompanied by the difficulties that HWA had in coping with the consequences of the fire, brought the project to an end.

This experience revealed the challenges and difficulties of "friendly hacking the business", since, when it comes to ideas and formats related to entrepreneurship, there seemed to be very few alternatives to the model of the independent and selfreliant woman. Even worse, there seemed to be no opportunity to experiment with 
alternative ideas as to what an entrepreneur is and what an enterprise can be. (What if an enterprise is driven by a collective? What if its aim is to generate social values and skills rather than profits?) The possibility of experimenting with alternative notions of enterprise and entrepreneurship was not just a matter of cultural or mental modes (collective vs. individual identity); it was also very much a matter of getting resources for and space within the business sector for experimenting with alternative models of entrepreneurship.

\section{Friendly hacking trial 3: The incubator}

The next attempt at friendly hacking was, once more, done within and with the municipality. (It is described in more detail in chapter 4.) Through establishing good relations with a civil servant that were inspired by design approaches through his previous work in the UK, we got the commission to explore how an incubator for social innovation could be structured and how its main features and support functions should be designed. We thought this incubator might make a difference for many invisible but resourceful stakeholders in the city. It was a very promising opportunity to build capacity within the municipality and establish a platform that could collaborate with stakeholders such as HWA. The process, bringing together civil servants, researchers, and grassroots initiatives (including HWA), developed a number of insights that were summed up for the municipality in a policy-briefing note. However, this process was then taken over by other actors. The final result was the establishment of a traditional incubator to support fairly traditional "close to market" business ideas. None of the grassroots initiatives that had been involved in the incubator process could fit into this structure. Although this intervention could also be seen as a severe failure, several civil servants were very disappointed with how the process had unfolded and wanted to continue to fight together with us to see if a structure that could collaborate with and support NGOs such as HWA could be established.

\section{Friendly hacking trial 4: The Innovation Forum}

After the incubator process, one of us got the opportunity to be embedded in a team of civil servants that was exploring the establishment of an Innovation Forum in which actors with complementary skills and knowledge could apply design-inspired methods to social challenges. The main task of the Innovation Forum was to develop a municipal structure that could respond to local challenges and initiatives from citizens. The process involved studying local, national, and international examples as well as investigating local grassroots organizations and ongoing municipal initiatives. Practitioners, researchers, and civil servants participated in workshops and seminars. Implementing design approaches within the municipality was regarded as promising; however, it also turned out to pose several challenges, one of which had to do with how some civil servants perceived the vocabulary of design. Insofar as the word 'design' itself 
connotes such things as product design and fashion design, using the word as we used it didn't make sense for many civil servants. A serious effort was therefore undertaken to use phrases more appropriate to their language and their culture: "The empathic perspective!" "Collaborative problem formulation!" "Test early and test again!" Finally, a report was produced with concrete suggestions on how to proceed. Once the report had been produced and the municipality owned the process, we believed, the process would lead to the creation of a structure that could finally collaborate with initiatives such as HWA. Again, however, nothing happened.

\section{Friendly hacking trial 5: Hacking financing bodies and indicators}

A substantial part of the funding that supported our collaboration with HWA came from Tillväxtverket (the Swedish Agency for Economic and Regional Growth, henceforth abbreviated SAERG), which channels money from EU Structural Funds to regional development projects. Our team was part of a larger project, Malmö Nya Medier, that had very distinct project goals (such as supporting regional growth) and indicators (such as creating a specified number of jobs and companies). During our interventions with HWA, it became obvious that these indicators weren't appropriate. The work with HWA wouldn't easily yield an indicator such as "a new company." At the same time, we could see that HWA had the potential to become a valuable resource for society.

While our project was unfolding, some external evaluators hired by SAERG criticized it severely and argued that our efforts should be more directly targeted toward activities likely to develop commercial businesses. Luckily, we found an ally in a group of researchers that had been assigned by the same financing body to do a meta-study on various projects financed by them. During their study, they could connect the rationale behind our work to a larger context of European policies regarding social cohesion and the connection between social integration and economic growth. According to the researchers, we had succeeded in establishing new forms of collaboration, had utilized unused competences, had empowered people, and had connected stakeholders in ways that had the potential to be models for future efforts: "Here, they have succeeded in something many regard as impossible, but it has not been considered to be valuable." (Stigendal 2012, 49, authors' translation) They concluded that the problem wasn't with how we operated, but with the fact that our activities were measured and evaluated over too short a time span and with indicators that were too limited. We still do not know how much of an impact this report will have, but we hope it will open up more opportunities for similar efforts.

\section{Further developments}

We have continued to collaborate with HWA on different projects and funding schemes, though perhaps not as intensively. For example, we did a "tele-crafting" session in which HWA members and some Swedish textile craft groups were connected through 
Skype to similar groups of women in Paris. HWA is also connected to two new larger projects in which we are extensively involved. One of these larger projects focuses on new ways of caring for the elderly; the other one takes a systemic perspective on physical and social investments in suburbs. We didn't have to invite HWA to take part in these projects. That group's visibility has increased, at least partly (we would argue) as a result of our stubborn engagement.

When it comes to friendly hacking, the most promising future paths seem to be related to the Commission for a Socially Sustainable Malmö (Stigendal and Östergren 2013), whose final report clearly states that one of the important strategies would be to continue the work that had been done toward establishing an Innovation Forum. The report also argued strongly for the importance of working with NGOs and the civic society. Other promising paths may also emerge from the alliances that we have built with fellow researchers at Malmö University. Thanks to this work, we are now engaged in exploring the possibility of an Institute for Participatory Citizenship, which could become a strong platform for addressing all the issues emerging from the work done with HWA.

\section{HWA and the bigger picture}

In this chapter, we have described infrastructuring and prototyping activities aimed at supporting the creative community HWA. The larger framework for this inquiry is how Living Lab the Neighborhood, by setting up collaborative design processes, can contribute to addressing different social challenges and can increase society's capacity to act. Within this framework, we have departed from grassroots efforts in the margins by collaborating with HWA. In this section we will connect the experiences from our collaboration with HWA to the findings of the Commission for a Socially Sustainable Malmö and discuss how HWA creates value and contributes to society and what kind of opportunities our work with them has generated.

First, as was stated above, the work HWA does has a very positive impact on its members and the area in which they live, but unfortunately the establishment doesn't acknowledge their activities. We don't think the prospects of a group such as HWA depend entirely on the members' own capabilities; we think they depend on how society is organized, how the economic system works, what cultural values are held, and what is considered normal. Therefore, in this section we will discuss the bigger picture in relation to HWA-what is considered to be work, what roles culture and civic society play, and what it means to be "integrated in the society."

One of the researchers involved in the Commission for a Socially Sustainable Malmö, the sociologist Mikael Stigendal, asserts the importance of problematizing how the parameters for urban development projects are set-for example, how and by whom a problem is defined, what the objectives are, what counts as results, what is considered normal, what actors are involved, and what is taken for granted: 
It has become an established perspective that problems are taken for granted. Unemployed seem not to work, while they in reality work in different forms (taking care of the home, family and relatives). Youngsters without grades seem to be without knowledge, when they rather have a lot of knowledge that we do not count or measure.

The population in some parts of Malmö that are characterized by high unemployment, poverty, and low grades seems to lack everything — while they rather might have and do very much, but things that do not fit into the exclusive community that the Swedish society has developed into. What is the problem? The answer to this question will be essential for the solutions. (Stigendal 2011, 8; translated from Swedish).

Stigendal (2012) argues that achieving social sustainability in Malmö will require questioning the notion of knowledge, the notion of work, and what "to be integrated" entails. He points to the need to take a holistic approach. Rather than working with one isolated problem, or just viewing a problem as rooted in individuals or communities, he argues, we should also consider the systemic and structural factors. He quotes the EU report Cities of Tomorrow:

The challenge of moving toward shared visions of holistic, sustainable development models is to a certain extent the challenge of reaching a better and shared understanding of urban realities. Overall objectives need to be understood in wider terms of final objectives-e.g. sustainable quality of life and liveability - and not only in the more narrow terms of the means to get there (e.g. economic growth, employment rate, income levels). (Hermant-de-Callataÿ and Svanfeldt 2011, 61)

The objectives that have been dominant drivers for society at large in the last 30 years, such as economic growth and employment, are more and more put into question. The growth paradigm has been criticized by Jackson (2009) and by Stiglitz, Sen, and Fitoussi (2009), and new objectives such as happiness (Abdallah et al. 2012) and equality (Wilkinson and Pickett 2009) have been proposed as more in line with the ideas of sustainability and quality of life. A major contribution to this field has been made by Amartya Sen (1986), who points out that material well-being is only one of the factors determining a person's quality of life. Specifically, Sen states, the standards of living are based on the possibilities of being and becoming that someone has. These so-called functionings depend on a person's internal capabilities, such as skills, but also on external things, such as social networks and access to services. In Sen's view, therefore, material well-being is only one of the factors that determine quality of life. Among the others are access to education, opportunity to have a social life, and having a role in one's community.

Stigendal (2012, 8; translated from Swedish) claims that the large-scale urban development programs that have been carried out in Malmö in the last ten years haven't been successful according to objectives like "sustainable growth" and reducing "social, ethnic and discriminating segregation." But, he asks, "what if the objectives were wrong?" (ibid., 28). He means that there has been a lot of innovative work carried out, but that, because it has been concerned with "happiness, meaning of life, community 
and belonging" (ibid., 30), it has only to a minor degree been taken into account. However, Stigendal views this work as a rich inspirational resource for "developing new forms of work, knowledge, democracy and participation" (ibid.).

We think that it is within this context that the activities of HWA should be considered, along with our collaboration with HWA in exploring "new forms" for contributing to society and for being considered as part of it. Looked at through this lens, HWA seems less problematic, less marginal, and more like a promising initiative with resources and potentials yet to be explored, developed, and acknowledged.

Below we will develop this new perspective by following Stigendal's reasoning regarding work, which is very close to the feminist tradition in economics. Some feminist economists have argued that wage labor and the market economy represent work and production only in part (Waring 1988; Gibson-Graham 1996; Gibson-Graham et al. 2013). They have argued that capitalism focuses only on profit-generating activities and that it ignores non-wage forms of work and production and the fact that these forms of work are essential for wage labor and market labor to exist. According to Gottschlich (2013), household work, caring for family members, and voluntary work within civil society are fundamental for the (re)production of society and for its functioning.

Stigendal $(2012,34)$ argues that work has been limited to gainful employment and that "other kinds of work," including voluntary work within civil society, studying, household work, and care work, aren't acknowledged. He again cites the Cities of Tomorrow report, which claims that "collective goods, i.e. public goods or goods that are not exchanged in the market but are self-produced and exchanged within small groups such as a family, club or social network or association, are of great importance, and are always underplayed in economic analyses that focus on GDP alone," and that "these play a crucial role in quality of life and are often significant in economic development" (Hermant-de-Callataÿ and Svanfeldt 2011, 50).

It is in this sphere that HWA operates, but their work doesn't count today. Stigendal $(2012,34)$ argues that this "other kind of work" could be developed into gainful employment, and that is the kind of exploration we have done with the women, responding to their wishes of becoming more integrated and contributing to society. We would, however, argue that they are already contributing, but their work is neither visible nor properly rewarded and recognized. Stigendal makes an interesting turn when he claims that the kind of work that civil society produces perhaps should not be developed into conventional employment. He means that it may be an "other kind of work" that can contribute to social welfare and cohesion.

But how to make a decent living? Could there be other ways to get acknowledged and paid for the work one does? Is there something in between living on welfare and being employed or running a business? Maybe it is here that our prototypes can make sense. We have failed in developing a conventional business, but we have explored and 
demonstrated new and alternative forms of work. But this also points to the need for new economic models for this kind of value creation.

We will now discuss how our infrastructuring and prototyping activities have affected HWA in relation to the findings of the Commission for a Socially Sustainable Malmö. First, we will relate infrastructuring to the concept of social capital.

In their discussion paper for the Malmö Commission, Maria Emmelin and Malin Eriksson claim that social capital includes "our social networks, our social support, possibilities to participate in society and degree of social kinship in our neighborhood" (2012, 11; translated from Swedish). Social capital can be an individual resource, but it also can be a collective resource consisting of people's participation in social networks, reciprocity, and trust between people: "When this exists," Emmelin and Eriksson write, "collaboration and mutual efforts between people is easier and leads to a well functioning society." The members of HWA could be said to have a rich "bonding" social capital, being well connected within their 400-member group and in their neighborhood, but they lack "bridging" social capital that might connect them with other groups and networks, institutions, and actors that could provide them with the resources, skills, and knowledge they lack. Here, we claim that our infrastructuring activities-such as connecting HWA with new and complementary actors, and the prototypes that made the women's capabilities visible-increased HWA's bridging social capital. Will Norman (2012) argues that bridging social capital helps an organization to reach beyond its immediate neighborhood, something that is very important if a community is to develop and become innovative.

As was mentioned above, our prototyping activities helped reveal potential in the women's activities and helped to connect them with new actors. Although the prototype with the refugee children and Attendo didn't achieve much, it created a rumor that the women had interesting qualities and had potential for performing such work, and that led the Migrationsverket (the Migration Board) to ask HWA whether it could perform a similar service for single immigrant women. Although that request didn't yield any real results, it shows that prototyping can reveal possibilities and spread them to a wider network of possible stakeholders.

HWA has new facilities and is occasionally doing some catering, but it hasn't yet become a cooperative business. However, doing catering more regularly than in the past, and thus getting a reputation and access to more potential customers, is a good start. Catering is also the most conventional of HWA's activities and perhaps the easiest activity to exploit. Even so, HWA will have to face competition from stronger and better-established actors.

We think that HWA's less conventional qualities and activities, such as the work with refugee children, still has a huge potential and could be developed further. In our view, this represents the real challenge, but also a unique possibility to generate value for the women, the children, and society. 


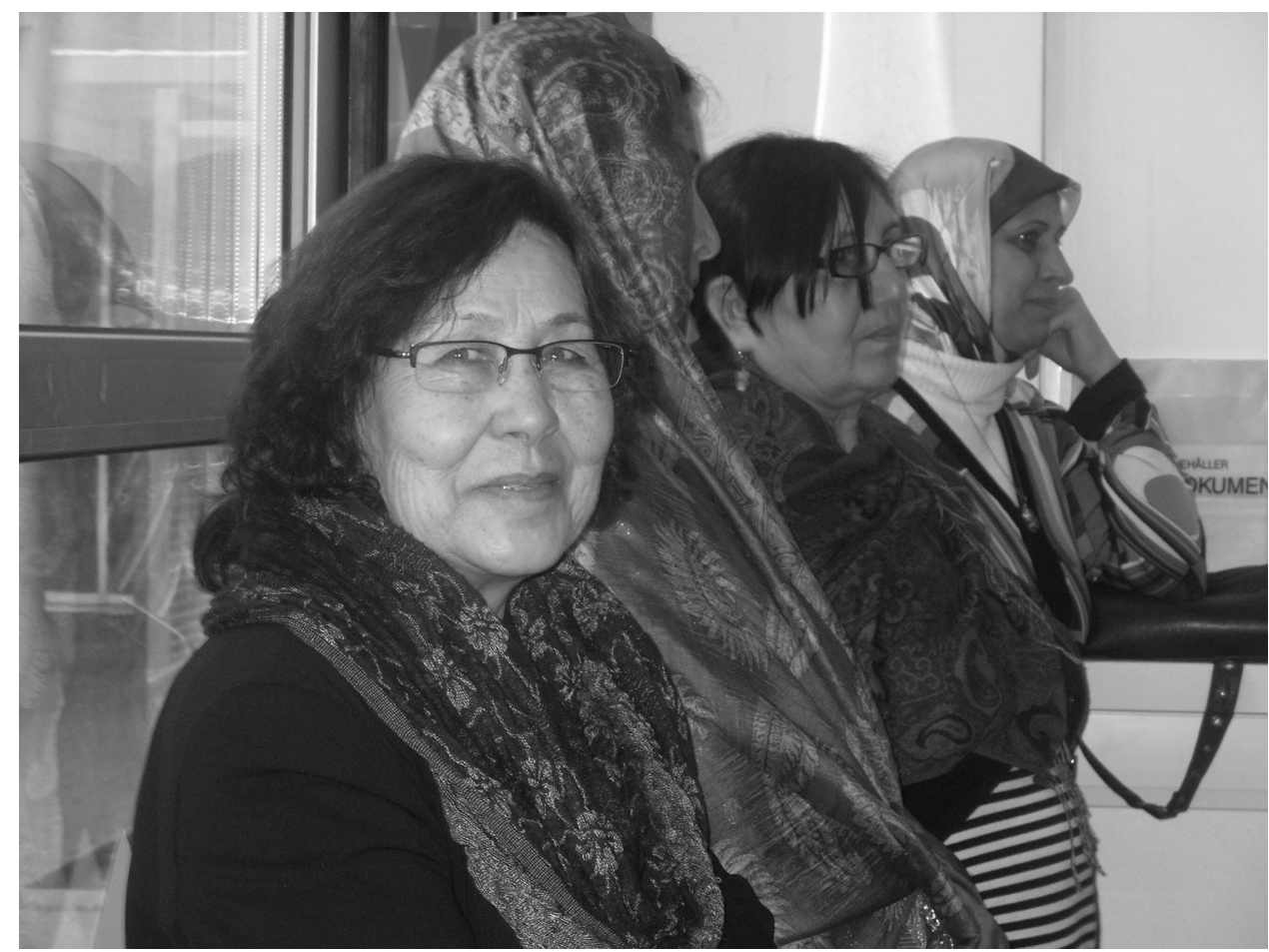

Figure 3.5

Four members of the HWA. Per-Anders Hillgren (CC:BY-NC).

\section{Designing Living Lab the Neighborhood}

The design trajectory, our journey, has shown that we couldn't have known from the beginning what kind of lab or framework project we would need when we initiated the first explorations. Even though we made a few strategic design decisions, such as explicitly taking an inclusive approach, most of our work has been spent on patchwork efforts to enable initiatives to grow from the bottom up, and on allowing for serendipity. Instead of following pre-defined plans, we navigated step by step among the opportunities and the obstacles we encountered. The whole process of building the lab could be seen as long-term reflective practice in which we have continuously matched different stakeholders and their respective agendas.

At times we were able to invite stakeholders to structured design workshops, but many of the encounters with stakeholders had to take other formats, often as iterative informal appointments. Still, we would argue that these encounters have been very designerly and that they could be seen as "artful inquiries" into the uncertain in which 
we continuously had to re-frame how situations could be understood and how these reframings affected our opportunities. The importance of these informal appointments also emerged in the matchmaking between HWA and the Mike Network; for example, the informal herb-picking trip to the woods turned out to be more successful than the structured workshops.

During the process of infrastructuring and building Living Lab the Neighborhood, we have been exploring the boundaries of a framework project. This has brought our attention not only to community-based interventions, but also to other levels of design engagements. We have been influenced by La 27 e Région's concept of "friendly hacking" aimed at influencing and possibly change the systemic levels of society. Even though more and more opportunities emerged for HWA to become a visible and acknowledged resource for society, the concept of friendly hacking became especially relevant when we could see that those opportunities didn't work within established societal structures.

We and La 27e Région aren't the only ones who argue that designers should take a more transformative role. Several design researchers have recently argued for challenging established structures instead of focusing on productivity, efficiency, experience, or improving services within existing societal structures (Botero and Saad-Sulonen 2013; DiSalvo 2012; Manzini and Staszowski 2013). However, when our design trajectory has reached these systemic levels, practical limitations emerged-for example, the fact that we have no mandate (or funding) to work with systemic change. Rather, we have to work with tactics, on in-between projects, and in informal alliances with civil servants and researchers who share our norms and interests.

Thinking about design and social innovation as long-term collaborations that could stretch between different sub-projects and different funding schemes has been important. Thanks to this long-term perspective, we have been able to build trust between diverse stakeholders, support mutual learning and dared to pick "tough" cases (i.e., cases that do not fit into existing structures and where you might end up without an immediate success story). This has also made it possible to slowly gain authority to work on more systemic levels (as exemplified by the above-mentioned project on physical and social investing in suburbs, in which we have been invited to work in alliances with researchers and civil servants who share an interest in systemic change).

What would be different if we had had a mandate to work on a systemic level from the beginning, as La 27e Région did? Or what if we had been embedded within and owned by the municipal structure, as Mindlab (an innovation unit in Denmark that are owned by and work with three ministries and one municipality) is? We believe that we probably wouldn't have been able to make the choices we made. Now that we are slowly reaching the systemic level, we are still rooted in the communities with which we have been working. 
This design trajectory also says something about how we, as design researchers located at a university, can position ourselves. As other design researchers have begun to argue, when you are approaching societal challenges you have to go beyond the traditional design project set-up, with its clear client-consultant relationship, and explore opportunities that may emerge among a variety of stakeholders with diverse agendas and needs (Botero and Saad-Sulonen 2013; Staszowski et al. 2013). This makes the designer role more complex than the role of a traditional innovation lab, such as a corporate lab that is steered and guided by private interests, or an embedded public-sector lab owned and controlled by a public administration (e.g., Mindlab). If a design lab doesn't have a clear client-consultant role, who will decide where and what processes to initiate, with whom, and from what perspective?

Our guiding principles were to be inclusive and to address diverse and conflicting agendas. However, we believe it was important to start with the embedded practices of particular communities. We paid considerable attention to whom we should start our collaboration with, and we tried to find stakeholders who were marginalized but also resourceful and who had extensive social capital within their networks. Although we started from the agendas, needs, and opportunities that we could see in HWA, which always was a point of reference for where we should navigate with our design interventions, we tried to balance their agendas with the interests of other stakeholders, such as the Mike Network or the municipality. This balancing act made the aspect of ownership central. In our work with HWA, we saw the importance of establishing stakeholders' ownership over the processes not only as a way to gain their temporal participation but also as a way to ensure a long-term commitment to the implementation of a new service or solution.

While working with Make It Real and the Mike Network, we stepped back to allow the members of Make It Real to take ownership (because they had an extensive network in the business field). We tried to argue that we could take a more active role because we knew that our experience with HWA could have been very useful in the process. Make It Real turned down our offer and we decided to respect that, although we could see some likelihood that their quite structured and business-focused process would be problematic.

Because different funding opportunities also affect what a lab can focus on, and because research labs depend on external funding, we had to respect the objectives and goals of different research calls from funding bodies. Still, as we saw in friendly hacking trial 5, we also need to challenge these goals and work on our own guidelines. SAERG, the agency that funded our work with HWA, hired external evaluators who during most of the project were quite critical and argued that we were too far from established models of business support. However, in their final report, they surprisingly stated that one of the strengths of our Living Labs was their broad definition of innovation and 
their strong focus on societal challenges. Their recommendation was that this focus should be developed further and be used to profile innovation in the region.

Given what we have learned, can we still work within the frame of traditional innovation projects dealing only with growth? Engaging in a traditional innovation project would mean accepting a vision that we know may limit our ability to consider what is regarded as legitimate value production within society and what is regarded as work. On the other hand, we know that traditional innovation projects provide a great opportunity to engage with and influence powerful actors such as funding bodies and policy makers. Then should we support pre-defined goals, or should we challenge them? Should we develop solutions that work within existing structures, or should we continue exploring alternatives? Should we continue the "friendly hacking" from within the existing structures?

When, during this long design trajectory, we encountered HWA and explored their capacities not from an existing template but much more freely, they could prove their skillfulness both to us, to refugee children, to other researchers and to (some) civil servants. Since then, HWA has been a point of reference for where we should navigate with our artful inquiries. As long as HWA cannot connect to the rest of society and become a more acknowledged resource, we have to continue the journey.

\section{References}

Abdallah, Saamah, Juliet Michaelson, Sagar Shah, Laura Stoll, and Nic Marks. 2012. The Happy Planet Index: 2012 Report. New Economics Foundation.

Bason, Christian. 2010. Leading Public Sector Innovation: Co-creating for a Better Society. Policy Press. Björgvinsson, Erling, Pelle Ehn, and Per-Anders Hillgren. 2010. Participatory Design and "Democratizing Innovation." In Proceedings of the Eleventh Participatory Design Conference, Sydney.

Björgvinsson, Erling, Pelle Ehn, and Per-Anders Hillgren. 2012. Agonistic Participatory Design: Working with Marginalised Social Movements. CoDesign 8 (2-3): 127-144.

Botero, Andrea, and Joanna Saad-Sulonen. 2013. Peer-Production in Public Services: Emerging Themes for Design Research and Action. In Public and Collaborative: Exploring the Intersection Of Design, Social Innovation and Public Policy, ed. E. Manzini and E. Staszowski. DESIS Network.

Brandt, Eva. 2006. Designing Exploratory Design Games-Can They Be the Guiding Framework for the Designer? In Proceedings of the Participatory Design Conference 2006, Trento.

Brown, Tim, and Jocelyn Wyatt. 2010. Design Thinking for Social Innovation. Stanford Social Innovation Review (http://www.ssireview.org).

Burns, Colin, Hilary Cottam, Chris Vanstone, and Jennie Winhall. 2006. Transformation Design (http://www.designcouncil.info/mt/RED/transformationdesign/TransformationDesignFinalDraft .pdf). 
Christiansen, Jesper, and Laura Bunt. 2012. Innovation in Policy: Allowing for Creativity, Social Complexity and Uncertainty in Public Governance (http://www.nesta.org.uk/publications/assets/ features/innovation_in_policy).

DiSalvo, Carl. 2012. Adversarial Design. MIT Press.

Emmelin, Maria, and Malin Eriksson. 2012. Kan socialt kapital "byggas in" in våra bostadsområden och därmed förbättra invånarnsa upplevda och mentala hälsa? Kommission för ett socialt hållbart Malmö.

Eriksson, Mats, Veli-Pekka Niitamo, Seija Kulkki, and Karl A. Hribernik. 2005. State-of-the-Art in Utilizing Living Labs Approach to User-Centric ICT Innovation-A European approach. Centre for Knowledge and Innovation Research, Helsinki School of Economics.

Florida, Richard. 2004. The Rise of the Creative Class. Basic Books.

Følstad, Asbjørn. 2008. Living Labs for Innovation and Development of Information and Communication Technology: A Literature Review. Electronic Journal for Virtual Organizations and Networks 10 (7): 99-131.

Gibson-Graham, J. K. 1996. The End of Capitalism (As We Knew It): A Feminist Critique of Political Economy. Blackwell.

Gibson-Graham, J. K., Jenny Cameron, and Stephen Healy. 2013. Take Back the Economy: An Ethical Guide for Transforming Our Communities. University of Minnesota Press.

Gottschlich, Daniela. 2013. Doing Away with "Labour": Working and Caring in a World of Commons. Keynote speech at Economics of the Commons Conference, Berlin.

Hamdi, Nabeel. 2004. Small Change: About the Art of Practice and the Limits of Planning in Cities. Earthscan.

Hermant-de-Callataÿ, Corrine, and Christian Svanfeldt. 2011. Cities of Tomorrow: Challenges, Visions, Ways Forward (http://ec.europa.eu/regional_policy/sources/docgener/studies/pdf/ citiesoftomorrow/citiesoftomorrow_final.pdf).

Hillgren, Per-Anders, Anna Seravalli, and Anders Emilson. 2011. Prototyping and Infrastructuring in Design for Social Innovation. CoDesign 7 (3-4): 169-183.

Jackson, Tim. 2009. Prosperity without Growth? The Transition to a Sustainable Economy (http:// www.sd-commission.org.uk/publications.php?id=914).

Jégou, François, and Ezio Manzini, eds. 2008. Collaborative Services: Social Innovation and Design for Sustainability. POLI.design.

Jégou, François, Stéphane Vincent, Romain Thévenet, and Anna Lochard. 2013. Friendly Hacking into the Public Sector: Co-Creating Public Policies within Regional Governments. Presented at Boundary-Crossing Conference on Co-Design in Innovation, Aalto University (http://www .slideshare.net/27eregion/friendly-hacking-into-public-sector). 
Kommonen, Kari-Hans, and Andrea Botero. 2013. Are the Users Driving, and How Open Is Open? Experiences from Living Lab and User Driven Innovation Projects. Journal of Community Informatics 9 (3).

Manzini, Ezio. 2007. A Laboratory of Ideas: Diffuse Creativity and New Ways of Doing. In Creative Communites, ed. A. Meroni. POLI.design.

Manzini, Ezio, and Francesca Rizzo. 2011. Small Projects/Large Changes: Participatory Design as an Open Participated Process. CoDesign 7 (3-4): 199-215.

Manzini, Ezio, and Eduardo Staszowski. 2013. Introduction. In Public and Collaborative: Exploring the Intersection of Design, Social Innovation and Public Policy, ed. E. Manzini and E. Staszowski. DESIS Network.

Meroni, Anna. 2007. Creative Communites: People Inventing Sustainable Ways of Living. Polidesign.

Murray, Robin, Julie Caulier-Grice, and Geoff Mulgan. 2010. The Open Book of Social Innovation. Young Foundation and Nesta.

Norman, Will. 2012. Adapting to Change: The Role of Community Resilience. Young Foundation.

Nystrom, Anna-Greta, and Seppo Leminen. 2011. Living Lab-A New Form of Business Network. In Proceedings of the 17th International Conference on Concurrent Enterprising.

Sanders, Elisabeth, and Pieter Jan Stappers. 2008. Co-creation and the New Landscapes for Design. CoDesign 4 (1): 5-18.

Sangiorgi, Daniela. 2011. Transformative Services and Transformation Design. International Journal of Design 5 (2): 29-40.

Schön, Donald. 1983. The Reflective Practitioner: How Professionals Think in Action. Basic Books.

Schön, Donald. 1987. Educating the Reflective Practitioner. Jossey-Bass.

Sen, Amartya. 1986. The Standard of Living. Tanner Lecture on Human Values, Cambridge University, 1985.

Stålbröst, Anna. 2008. Forming Future IT: The Living Lab Way of User Involvement. Doctoral thesis, Luleå University of Technology.

Staszowski, Eduardo, Scott Brown, and Benjamin Winter. 2013. Reflections on Designing for Social Innovation in the Public Sector: A Case Study in New York City. In Public and Collaborative: Exploring the Intersection of Design, Social Innovation and Public Policy, ed. E. Manzini and E. Staszowski. DESIS Network.

Stigendal, Mikael. 2011. Malmö—de två kunskapsstäderna. Kommission för ett socialt hållbart Malmö.

Stigendal, Mikael. 2012. Malmö—från kvantitets- till kvalitetskunskapsstad. Kommission för ett socialt hållbart Malmö. 
Stigendal, Mikael, and Per-Olof Östergren. 2013. Malmös väg mot en hållbar framtid. Hälsa, välfärd och rättvisa. Kommission för ett socialt hållbart Malmö.

Stiglitz, Joseph, Amartya Sen, and Jean-Paul Fitoussi. 2009. Report of the Commission on the Measurement of Economic Performance and Social Progress.

von Hippel, Eric. 2005. Democratizing Innovation. MIT Press.

Waring, Marilyn. 1988. If Women Counted: A New Feminist Economics. Harper \& Row.

Wilkinson, Richard G., and Kate Pickett. 2009. The Spirit Level: Why More Equal Societies Almost Always Do Better. Allen Lane. 
